\title{
CORREIOS AÉREOS MILITARES: ALIADOS DA ASSISTÊNCIA SOCIAL DA FAB NA AMAZÔNIA*
}

\section{MILITARY AIR MAIL AS ALLIES OF FAB SOCIAL ASSISTANCE IN THE AMAZON}

\section{Claudia Maria Sousa Antunes ${ }^{* * *}$ Maria Lúcia Valada de Brito**}

Resumo: O presente trabalho visa empreender o estudo do processo de criação e implantação do Correio Aéreo Nacional, a princípio como um meio dual, de adestramento dos pilotos militares e de integração nacional e que, em determinado momento, tornou-se um veículo para a execução de ações assistencialistas, por parte do Governo Federal. A História do Correio Aéreo Nacional (CAN) relaciona-se com a inclusão social de populações da Amazônia e a integração nacional. Busca-se resgatar uma parte da História da aviação desde a escola francesa do ensino de pilotos no Campo dos Afonsos até sua dissociação e transferência do Exército para a Aeronáutica brasileira. Parte-se do princípio de que o processo de escolhas do Comando da Aeronáutica (COMAER), além de ser estratégico, pode salvar vidas.

Palavras-chave: Correio Aéreo Nacional. Amazônia. Integração Nacional.

Abstract: The present work aims to undertake the study of the process of creation and implementation of the National Air Mail, initially as a dual means, of training of the military pilots and of national integration and that, in a certain moment, became a vehicle for the execution of welfare actions by the Federal Government. The history of the National Air Mail (CAN) relates to the social inclusion of Amazonian populations and national integration. It seeks to rescue a part of the history of aviation from the French school of pilots teaching in Campo dos Afonsos until its dissociation and transfer of the Army to the Brazilian Aeronautics. It is assumed that the choice process of the Air Command (COMAER), besides being strategic, can save lives.

Keywords: Correio Aéreo Nacional. Amazon. National Integration.

\footnotetext{
Este trabalho é parte de dissertação de mestrado submetida ao Programa de Pós-Graduação em Ciências Aeroespaciais da Universidade da Força Aérea - UNIFA/RJ.

** Possui graduação em Letras Português Literaturas pela Universidade Federal do Rio de Janeiro (1988), Mestrado em Letras (Letras Vernáculas) pela Universidade Federal do Rio de Janeiro (1997) e Doutorado em Letras (Letras Vernáculas) na Universidade Federal do Rio de Janeiro (2016). Atualmente, é Professora Adjunta da Universidade da Força Aérea (UNIFA) e pesquisadora do Núcleo de Estudos Interdisciplinares em Ciências Aeroespaciais (NEICA).

** Possui Mestrado em Ciências (grande área de Ciências Políticas e Relações Internacionais) do Curso de Mestrado Profissional em Ciências Aeroespaciais da UNIFA (2018), Curso de extensão universitária em Tutoria em EAD: Teorias e Práticas (2018).
} 


\section{INTRODUÇÃO}

O Tenente-Brigadeiro do Ar Nélson Freire Lavanère-Wanderley, ao narrar a história da Força Aérea Brasileira, afirma que o mérito do Correio Militar foi o de propiciar aos pilotos brasileiros a oportunidade de descobrirem, por meios aéreos, o interior do Brasil (LAVANÈRE-WANDERLEY, 1975, p. 137). Essa afirmação diz respeito a uma das instituições que foram criadas com a finalidade de integrar efetivamente o Brasil, fazendo uso da, à época, relativamente nova ferramenta da tecnologia: o avião. Tal instituição, criada no início dos anos 1930 e que ainda hoje tem cumprido esse papel, é o Correio Aéreo Nacional (CAN).

Para que se possa ter uma noção exata do significado da criação dos Correios Aéreos das Forças Armadas, nos anos 1930, é preciso levar em conta que o Correio Aéreo Nacional era considerado um elo importante na integração do território nacional. (LAVANÈRE-WANDERLEY, 1975).

Destarte, é possível compreender-se, a partir da citação acima, quão importante passava a ser, para uma cidade do interior do Brasil, a criação de uma escala do CAN em seu aeródromo ou aeroporto. À época, o Brasil praticamente não dispunha de empresas de transporte aéreo, e a rede de estradas de rodagem era de todo insuficiente. As comunicações com o interior do Brasil eram supridas por cerca de $14.000 \mathrm{~km}$ de ferrovias e, principalmente, pela navegação costeira, também chamada de cabotagem, e pela navegação lacustre e fluvial, está muito dependente do regime de cheias e vazantes dos rios.

O processo que levou à criação e implantação do CAN, contudo, foi gradativo, à medida que os meios das Aviações Militar e Naval e, após 1941, da Força Aérea Brasileira (FAB), assim o permitiam. Tal processo amadureceu ao longo de aproximadamente 27 anos.

\section{A CRIAÇÃO DAS AVIAÇÕES MILITAR E NAVAL}

A instituição da Aeronáutica denominada Correio Aéreo Nacional (CAN), criada no início da década de 1930, remonta suas origens às Aviações Militar e 
Naval, as quais, por sua vez, surgiram na segunda década do século XX. A criação do CAN, ainda como Correio Aéreo Militar (CAM), teve como motivação inicial o desejo dos oficiais da Aviação Militar, os quais almejavam libertar-se do cilindro teórico de $10 \mathrm{~km}$, em torno do Campo dos Afonsos, distância essa estabelecida pelos instrutores da Missão Militar Francesa, como distância máxima de voo para os pilotos brasileiros. (LAVANÈRE-WANDERLEY, 1975).

Coube à Marinha do Brasil a iniciativa pioneira de criar e ativar, nas Forças Armadas, um serviço de aviação.

Foi à Marinha que coube a primazia de criar e organizar o primeiro núcleo militar de aviação, durante a I Guerra Mundial, no Governo do Presidente Wenceslau Braz, sendo Ministro da Marinha o Almirante Alexandrino; Decreto no 12.167, de 23 de agosto de 1916. (LAVANĖRE-WANDERLEY, 1975, p. 53).

A Escola de Aviação Naval estava localizada, de início, no antigo Arsenal de Marinha, na Praça Mauá; no ano seguinte, a Escola é transferida para a llha das Enxadas, na Baía de Guanabara; finalmente, em 1924, passa a operar na Ponta do Galeão, na llha do Governador, em instalações construídas para esse fim. No Galeão, a Escola desempenhou sua atividade, até o ano de 1941. (LAVANÈREWANDERLEY, 1975).

Figura 1 - Escola de Aviação Naval - Ponta do Galeão

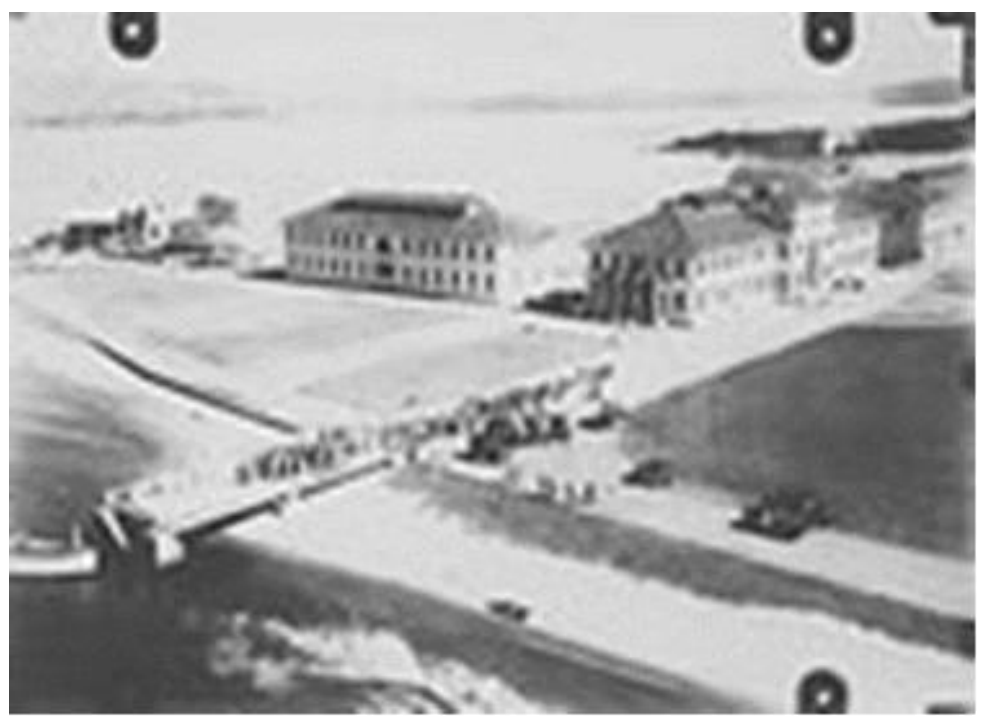

Fonte: Lavanère-Wanderley (1975). 
Inicialmente, a Escola operava com três hidroaviões Curtiss, Modelo F, os quais foram adquiridos nos Estados Unidos, e montados no Brasil, com o apoio do mecânico e piloto civil norte-americano Orthon Hoover, o qual passou a ser também o instrutor de voo na nova escola. Ao final de 1916, é formada a primeira turma de pilotos aviadores navais, constituída pelos Primeiros-Tenentes Antônio Augusto Schorcht, Raul Ferreira Vianna Bandeira, Virginius Brito De Lamare, e ainda pelo Segundo-Tenente Victor de Carvalho e Silva. O Tenente Schorcht veio a tornar-se, em fevereiro de 1917, o primeiro militar brasileiro qualificado como instrutor de voo. (LAVANÈRE-WANDERLEY, 1975).

Após o término da Primeira Guerra Mundial, em novembro de 1918, havia grandes excedentes de estoques de aeronaves e peças de reposição, nos países vencedores. A par disso, nesses países, Reino Unido e França, havia pilotos navais, veteranos da guerra, bastante experimentados. Por esse motivo, a Aviação Naval pôde reequipar-se e, ao mesmo tempo, enviar seus oficiais para serem formados e igualmente aperfeiçoar-se nos Estados Unidos, Reino Unido e Itália. "A Aviação Naval entra, então, numa fase de consolidação e expansão". (LAVANÈREWANDERLEY, 1975, p. 59).

Essa fase de expansão da Aviação Naval durou até 1924, tendo sido então refreada devido aos acontecimentos políticos, em especial durante o Governo do Presidente Artur Bernardes. No referido período, conseguiram-se formar 38 pilotos aviadores navais, tendo ainda voado, somente nos anos de 1919 e 1920, 1.249 horas de voo. (LAVANÈRE-WANDERLEY, 1975).

Destarte, a análise dos fatos relativos à criação da Aviação, na Marinha, denota um esforço concentrado na implantação desse serviço. A princípio, durante a guerra, esse esforço foi tímido, em face das demandas do esforço de guerra, quer no Brasil, quer nos demais países beligerantes. A partir do término do conflito, no entanto, a disponibilidade de excedentes de guerra, quer de material como de pessoal, permitiram uma expansão rápida e intensa, que foi, no entanto, reduzida por fatores exógenos à própria Aviação. Foi essa expansão de meios e doutrina que permitiu, a partir de 1934, que a Marinha criasse seu próprio Correio Aéreo.

Embora a Marinha tivesse criado sua Escola de Aviação ainda durante a guerra, o Exército, por sua vez, aguardou o término do conflito para iniciar a 
implantação efetiva de sua Aviação Militar. Os primeiros passos para tal, no entanto, foram dados ainda durante a conflagração: em agosto de 1918, autoridades militares brasileiras na França assinaram com o governo francês um acordo para o envio, ao Brasil, de uma Missão Militar de Aviação, composta por pilotos e mecânicos, além do equipamento necessário, tudo com a finalidade de aqui implantar-se uma escola de aviação.

A referida escola é citada no Aviso Ministerial $n ² 1.463$, de 21 de novembro de 1918, do Ministro da Guerra,

\begin{abstract}
Sr. Chefe do Departamento de Pessoal da Guerra: Declaro-vos, para os devidos fins, que o serviço de Aviação Militar fica subordinado à Repartição do Estado-Maior do Exército, competindo-Ihe, portanto, organizar com urgência esse serviço e bem assim o regulamento da escola de aviação, cujo material acaba de chegar da Europa; sendo que ambos esses trabalhos deverão ser feitos de acordo com a missão francesa, para esse fim contratada, à qual caberá a direção técnica da referida Escola. Saúde e fraternidade, Alberto Cardoso de Aguiar. (BRASIL, 1918).
\end{abstract}

Tal citação resume três ideias relevantes acerca da Escola de Aviação Militar. A primeira delas diz respeito à subordinação do serviço de Aviação Militar e, portanto, da própria Escola, ao Estado-Maior do Exército, órgão de planejamento e direção geral da Força. A segunda ideia relaciona-se ao fato de ser a Aviação Militar um serviço, e não uma arma, dessa forma sendo considerada uma estrutura de apoio, e não de combate. Finalmente, o Aviso estipula que a Missão Francesa, recentemente contratada, será encarregada da direção técnica da Escola. Este último fato viria a ter influência decisiva na posterior criação do Correio Aéreo Militar.

A Escola de Aviação Militar vem a ser efetivamente ativada em 1919, no local conhecido como Campo dos Afonsos, no mesmo local onde, em 1912, houve uma tentativa em criar-se a Escola Brasileira de Aviação, por parte de aviadores italianos. Essa escola teve vida efêmera, em virtude de desacertos entre seus proprietários e o Ministério da Guerra, que deveria financiá-la. (LAVANĖREWANDERLEY, 1975).

No dia 22 de janeiro de 1920, graduou-se a primeira turma de pilotosaviadores militares, composta por doze oficiais do Exército Brasileiro. A segunda turma, formada ainda em 1920, era formada por um tenente e doze sargentos, cabos e soldados do Exército, bem como por três oficiais do Exército Uruguaio. O 
treinamento de pilotagem era levado a efeito, nos dois primeiros anos de existência da Escola, em aeronaves francesas, excedentes da Primeira Guerra Mundial.

A Escola de Aviação Militar teve um período de notável crescimento, no período entre 1919 e 1924, tendo sido inclusive empregada no combate à Revolução de 1924, em São Paulo. Em julho daquele ano, pilotos e aeronaves da Escola realizaram missões de reconhecimento, panfletagem e até mesmo de rudimentar bombardeio, contra as forças revolucionárias. Assim, esse episódio pode ser considerado o batismo de fogo da jovem Aviação Militar. Acerca desse período, assim se refere Lavanère-Wanderley,

Estavam assim plantadas, definitivamente, as raízes da Aviação Militar, que passou a contar, no Campo dos Afonsos, com uma base adequada, abrangendo um amplo aeródromo, hangares, quartéis e oficinas; o pessoal formado nesse período constituiu um importante núcleo de oficiais e sargentos pilotos-aviadores e mecânicos e especialistas que durante muitos anos iriam prestar relevantes serviços à Aviação Militar e, mais tarde, à Força Aérea Brasileira. (LAVANĖRE-WANDERLEY, 1975, p. 90).

À parte as ações da Revolução de 1924, o mandato do Presidente Artur Bernardes (1922-1926) foi de estagnação para a Aviação Militar, por motivos políticos. A partir de posse de Washington Luís, nos primeiros dias de 1927, a Aviação Militar iniciou um novo período de grande expansão. 
Figura 2 - Escola de Aviação Militar - Campo dos Afonsos - 1938

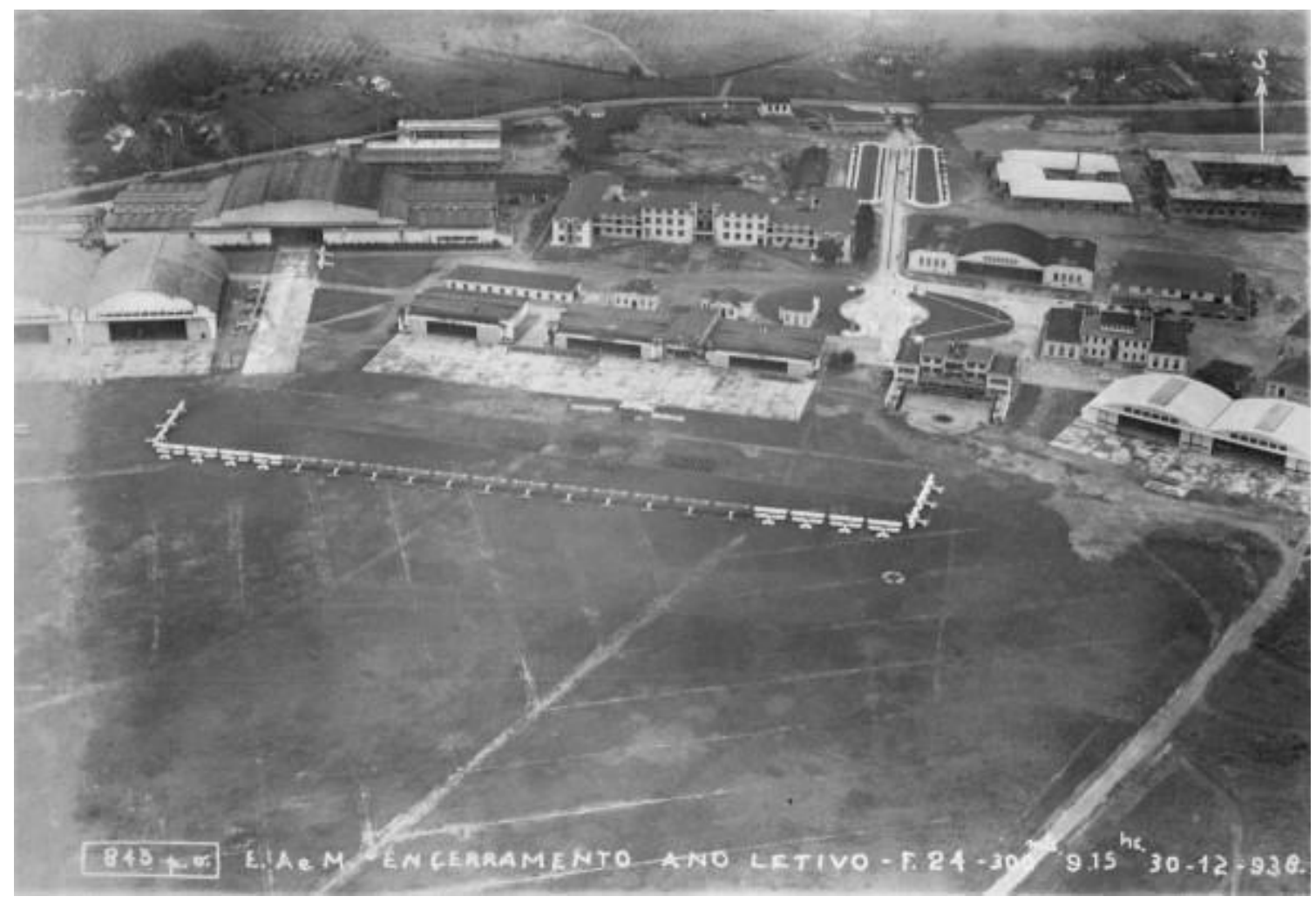

Fonte: Lavanère-Wanderley (1975).

A Lei oㅜ 5.168, de 13 de janeiro de 1927, criou, no seio do Exército, uma nova Arma, a Arma de Aviação, a qual passou a ombrear com as Armas já existentes, Infantaria, Cavalaria, Artilharia e Engenharia, passando a ser denominada a quinta Arma. Desse modo, a Aviação passa a ter um papel significativo no combate, e deixa de ser um serviço de apoio. O preparo, emprego e administração da nova Arma passa a ser encargo de um órgão central, a Diretoria de Aviação Militar. Esta, sob o comando de um oficial-general, foi instalada, ainda em 1927, nas dependências da Escola de Estado-Maior do Exército, à rua Barão de Mesquita, no bairro da Tijuca (Rio de Janeiro). Seu primeiro Diretor foi o General de Brigada Álvaro Guilherme Mariante. O Diretor era assessorado por um Estado-Maior composto por oito oficiais, dentre eles o então Major Pedro Aurélio de Góes Monteiro, o qual viria a tornar-se, junto com Eurico Gaspar Dutra, um dos grandes líderes militares durante o primeiro período Vargas (1930-1945). 
A partir de 1927, com a criação da Arma de Aviação, a Escola de Aviação Militar passa a conhecer um período de franca expansão. Em 15 de novembro daquele ano, por decreto presidencial, um grupo de 36 oficiais, já diplomados como pilotos ou observadores aéreos, são transferidos para a arma de Aviação. Cabe salientar que, dentre esses, estava o Primeiro-Tenente Eduardo Gomes, já considerado um herói nacional, por sua participação na Revolta de 1922, como um dos "Dezoito do Forte". Posteriormente, Eduardo Gomes teria significativa participação na criação do CAN e em outros episódios da vida militar e política nacional.

Nos anos de 1929 e 1930, mais 15 oficiais, provenientes de outras Armas do Exército, seriam transferidos para a arma de Aviação. No ano de 1928, um importante marco é atingido: são formados na Escola os primeiros Aspirantes a Oficial da Arma de Aviação. São sete Aspirantes, egressos da Escola Militar do Realengo, que cumpriam seu último ano de instrução no Campo dos Afonsos. A segunda turma é formada em 19 de janeiro de 1929, com dez Aspirantes.

No que tange aos instrutores da Escola, e conforme já mencionado, a Direção Técnica da Escola de Aviação Militar era exercida, desde sua criação, por um oficial do Exército Francês, membro da Missão Militar Francesa de Aviação. Em 1927, os membros dessa Missão eram,

\footnotetext{
Tenente-Coronel Henry Jeauneaud: Chefe da Missão e Diretor Técnico da Escola de Aviação Militar; Major Marc Benoit Terrasson: Chefe da Instrução de Pilotagem; Major Eugene Robini: Instrutor de Tática Geral e Aérea; Major François Dordilly: Instrutor de Navegação Aérea; Major-Engenheiro Leon M.A.A. Montrelay: Instrutor de Técnica de Aviação; Major Georges Joseph Mairey: Instrutor de Tiro e Bombardeio; Tenentes-Mecânicos Mercier e Matier: Instrutores de Conhecimentos Técnicos e Mecânica. (LAVANĖREWANDERLEY, 1975, p. 96).
}

Assim, pode-se inferir que havia oito instrutores franceses na Escola, número significativo, ao se considerar que as duas primeiras turmas formadas na Escola somavam apenas 17 Aspirantes, o que perfaz uma média de 2,1 alunos para cada instrutor francês. Essa elevada ratio, aliada ao fato de a Direção Técnica da Escola ser desempenhada sempre por um oficial superior francês, aponta para o fato de que a influência francesa na instrução de pilotagem era significativa. Tal 
influência viria a ter consequências anos mais tarde, quando da criação do Correio Aéreo Militar (CAM).

Embora já houvesse, no início dos anos 1930, uma Diretoria de Aviação Militar, no seio do Ministério da Guerra, a única Unidade de Aviação existente era a própria Escola, cuja missão era o preparo dos meios da Aviação Militar, em termos de pessoal e de material. Carecia a Arma de Aviação de uma unidade operativa, voltada para o emprego dos meios aéreos. Em 21 de maio de 1931, por meio do Decreto $n^{\circ}$ 20.023, é criado o Grupo Misto de Aviação, com sede no Campo dos Afonsos. O Grupo recebeu aeronaves francesas Potez 25 TOE, para emprego bélico, e ainda os Curtiss Fledgling, para treinamento. Seu primeiro Comandante foi o então Major Eduardo Gomes; com ele, vieram mais quatorze oficiais, para compor os quadros da nova unidade.

Com esses meios, no mesmo ano de 1931, o Grupo Misto de Aviação daria início a um serviço que se tornou do maior significado, para a FAB e para o Brasil: o Correio Aéreo Militar (CAM), embrião do futuro Correio Aéreo Nacional, o CAN.

\section{O CORREIO AÉREO MILITAR}

A criação do Correio Aéreo Militar (CAM) pode ser vista como consequência de dois fatores distintos. O primeiro deles foi a Grande Depressão, fenômeno de caráter econômico, com fortes efeitos sociais, e que assolou praticamente todas as economias capitalistas, a partir de 1929, quando acontece a quebra da Bolsa de valores de Nova York. (PERISSINOTTO, 2000).

Após o início da Depressão, que se prolongou até o final dos anos 1930, as nações capitalistas tiveram que reduzir fortemente seus orçamentos. O impacto nos orçamentos militares, assim, seria inevitável. O Brasil foi especialmente atingido pela Depressão, na medida em que o principal comprador do café brasileiro, os Estados Unidos da América, reduziu suas importações do produto em cerca de $47 \%$, entre os anos de 1930 e 1934. Cabe salientar que a exportação do café, nos anos 1920 e 1930, respondia por $68 \%$ das receitas de exportação do Brasil. (FUNDAÇÃO GETÚLIO VARGAS, [2010]). 


\begin{abstract}
Nascido da inspiração de um grupo de oficiais idealistas como Eduardo Gomes, Lemos Cunha e Casimiro Montenegro, o Correio Aéreo Militar encontrou, desde logo, o mais decidido apoio do Ministro da Guerra, General José Fernando leite de Castro, que vinha marcando a sua administração por uma série de iniciativas, pelas quais o Exército se tornava menos pesado ao erário nacional, prestando serviços públicos em tempo de paz. (LAVANÈRE-WANDERLEY, 1975, p. 137, grifo nosso).
\end{abstract}

Dentro desse contexto, é razoável supor-se que a utilização do Exército para realizar um serviço eminentemente civil, como o transporte de correspondências, viria a justificar, perante a Nação, o dispêndio com o orçamento militar, num momento em que não se avizinhavam graves ameaças no contexto externo sulamericano, e o país vivia grave situação econômica.

Outro fator que contribuiu decisivamente para a criação do CAM, talvez o mais importante, foi a ânsia incontida dos jovens aviadores militares de se libertarem do cilindro teórico, de raio de $10 \mathrm{~km}$ em torno do Campo dos Afonsos, que as orientações anteriores tinham criado como limite da quase totalidade dos voos militares. (LAVANÈRE-WANDERLEY, 1975, p. 137).

As orientações anteriores, às quais a citação se refere, eram as diretrizes restritivas emanadas pela Missão Francesa, que controlou a instrução de voo da Escola de Aviação Militar até o ano de 1930, e que não permitiam voos além da área dos Afonsos, exceto em situações especiais.

Uma vez tomada a decisão de se criar o Serviço Postal Aéreo Militar (SPAM), nome logo depois trocado para Correio Aéreo Militar (LAVANÈREWANDERLEY, 1975), a missão foi atribuída à única unidade aérea operativa da qual o Exército dispunha: o Grupo Misto de Aviação. As aeronaves selecionadas foram os Curtiss Fledgling, na falta de meios mais adequados.

A 12 de junho de 1931, tem início a primeira missão do CAM. Os Tenentes Casimiro Montenegro Filho e Nélson Freire Lavanère-Wanderley decolam do campo dos Afonsos e, após um voo de 5h20min, pousam, ao anoitecer, no Hipódromo da Mooca, em São Paulo. A mala postal que carregavam continha apenas duas cartas. Mas a missão fora cumprida: estava "inaugurado" o serviço do Correio Aéreo Militar. Após essa data, a linha pioneira do CAM, Rio de Janeiro - São Paulo - Rio de Janeiro, passou a ser realizada com a frequência de três vezes por semana. 
Figura 3 - Curtiss Fledgling K 263

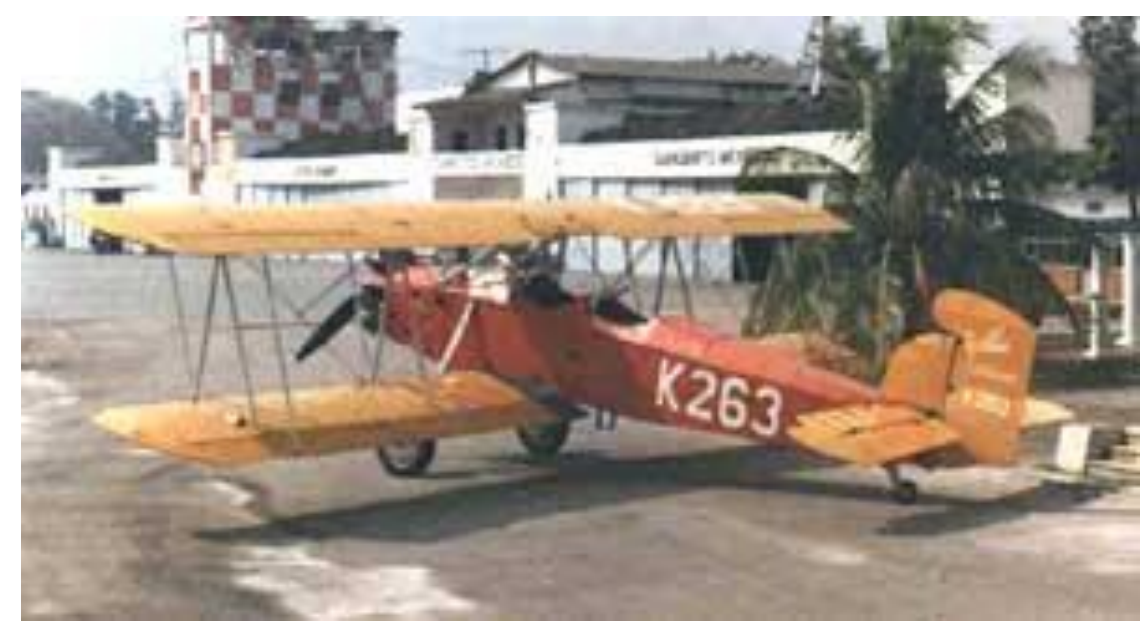

Fonte: Reservaer (2017).

Em setembro de 1931, iniciam-se os preparativos para a nova linha: a Linha de Goiás. O voo inaugural é realizado em 19 de outubro de 1931, com início nos Afonsos e escalas em São Paulo, Ipameri, Ribeirão Preto, Uberaba, Uberlândia, Araguari e Leopoldo Bulhões, chegando no ponto final, a cidade de Goiás (hoje Goiás Velho), em 21 de outubro. A seguir, diversas outras linhas são inauguradas: Linhas São Paulo - Mato Grosso e São Paulo - Curitiba, em 1932; Linha do São Francisco, em 1933, ligando o Rio de Janeiro a Fortaleza $(2.500 \mathrm{~km})$. Esta linha, por sua extensão, passou a ser uma das mais importantes do CAM. (LAVANÈREWANDERLEY, 1975).

Os anos 1930 são de grande expansão para o CAM. Outras linhas são criadas: Fortaleza - Teresina (1933), Uruguaiana - Porto Alegre (1934), Fronteira do Mato Grosso (1934) e a Linha Curitiba - Foz do Iguaçu (1935). Sobre esta última linha, cabe citar Lavanère-Wanderley,

Em 23 de março de 1935, foi inaugurada, com grande repercussão para as populações interessadas, a Linha do Correio Aéreo Militar ligando Curitiba a Foz do Iguaçu [...] naquela época, todo o oeste do Estado do Paraná estava coberto por densa floresta, e as comunicações por via terrestre eram praticamente inexistentes; durante vários anos, o elo mais importante com aquela região estratégica das nossas fronteiras, passou a ser o avião semanal do Correio Aéreo Militar. (LAVANÈRE-WANDERLEY, 1975, p. 147, grifo nosso). 
A citação exemplifica uma situação bastante comum para muitas das localidades servidas pelo CAM: isolamento, deficiência de comunicações, inexistência de ferrovias e rodovias, enfim, situações que, na época, somente o avião, com sua velocidade e capacidade de ultrapassar os obstáculos do relevo e da hidrografia, poderia suplantar.

Além disso, deve-se considerar que

\begin{abstract}
Em 1931, do ponto de vista da sua unidade política, o Brasil era um arquipélago composto de ilhas representadas pelos núcleos de populações perdidos na vastidão do Território Nacional; as linhas do Correio Aéreo Nacional, em muitos casos, foram os primeiros elos a integrar esses componentes da nacionalidade brasileira, até então privados de meios adequados de comunicação. (LAVANĖRE-WANDERLEY, 1975, p. 161, grifo nosso).
\end{abstract}

Cabe salientar que, nos anos 30, havia apenas uma empresa aérea privada, pertencente ao Sindicato Condor, que fazia uma linha para o interior do Brasil, no trecho São Paulo - Corumbá; as outras (poucas) empresas aéreas, como a VARIG, somente operavam linhas para cidades no litoral. (LAVANÈRE-WANDERLEY, 1975).

Um marco importante para o CAM foi atingido em 14 de julho de 1935: a cidade de Belém passou a ser servida pelo prolongamento da Linha Fortaleza Teresina. Enfim, o CAM chegava à Amazônia. Em 1937, cria-se a Linha de Belém a Oiapoque, no Amapá, extremo norte do Brasil. Em 31 de janeiro de 1939, é feita a primeira viagem na Linha do Tocantins, prolongamento da Linha de Goiás; assim, o Rio de janeiro ficava ligado a Belém pelo interior, sem a necessidade de cumprir-se a demorada rota pelo litoral do Nordeste. As cidades atendidas pela nova linha eram, dentre outras, Santa Luzia, Formosa, Palmas, Peixe, Porto Nacional, Tocantínia, Pedro Afonso, Carolina, Boa Vista, Imperatriz, Marabá, Cametá e Belém. (LAVANÈRE-WANDERLEY, 1975). 
Figura 4 Linhas do CAM - 1935

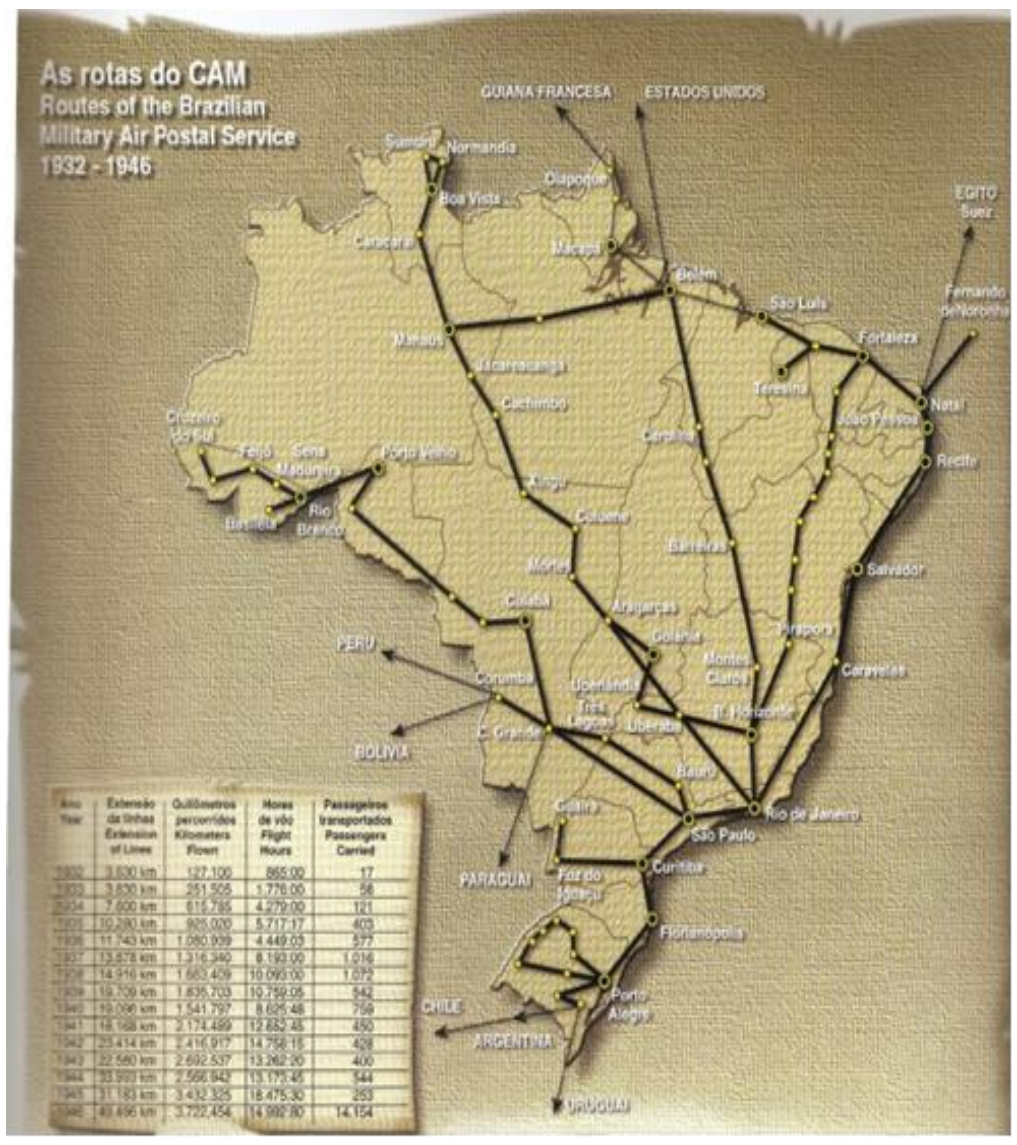

Fonte: Lorch (2000).

Em 1934, também a Marinha criou seu serviço de correio, denominado Correio Aéreo Naval. Este serviço atendia, principalmente, o litoral sul do Brasil. Sua linha estendia-se, inicialmente, do Galeão até Florianópolis, com escalas em Santos e Paranaguá. Em 1936, a linha estendeu-se até Rio Grande. Dessas cidades saíam linhas locais; por exemplo, de Rio Grande irradiavam-se linhas para as localidades de Jaguarão, Pelotas e Santa Vitória do Palmar, está no extremo sul do Brasil.

O Correio Aéreo Naval não teve a mesma participação que o CAM em integrar o país, posto que, pela própria característica da Marinha e do seu material (principalmente hidroaviões), de operar no mar e em regiões banhadas por águas interiores, as localidades servidas não eram tão isoladas. Muitas delas, como Santos, Paranaguá, Florianópolis, Rio Grande, Laguna, Jaguarão, Pelotas, Itajaí, e outras, já eram há tempos servidas por empresas de navegação de cabotagem, 
fluvial e lacustre, bem como por ferrovias que foram construídas no final do século XIX e inícios do Século XX. (LAVANÈRE-WANDERLEY, 1975).

Dessa forma, fica patente a importância do CAM como fator de integração nacional e de adestramento para os pilotos da Aviação Militar. A área mais distante dos grandes centros, a Amazônia, ainda era, no entanto, apenas parcialmente atendida por poucas linhas existentes. A criação do Ministério da Aeronáutica e da Força Aérea Brasileira, no entanto, viria mudar essa situação, interiorizando ainda mais as linhas do Correio Aéreo, que viria então a se tornar "Nacional", e não mais "Militar".

\section{O CORREIO AÉREO NACIONAL}

A criação do Ministério da Aeronáutica e da Força Aérea Brasileira, em 1941, ensejou a fusão da Aviação Militar e da Aviação Naval. Consequentemente, também foram unidos o Correio Aéreo Militar e o Correio Aéreo Naval. Dessa fusão nasceu o órgão que teria grande atuação nos destinos do Brasil: o Correio Aéreo Nacional, popularmente conhecido pela sua sigla CAN.

Ao estruturar-se o novo Ministério, foi criada a Diretoria de Rotas Aéreas (DR). Essa Diretoria respondia por numerosas tarefas, dentro da Aeronáutica, tais como a Proteção ao Voo, ou seja, a instalação, operação e manutenção de equipamentos como torres de controle, rádios, telégrafo, radiofaróis e outros auxílios à navegação aérea. Outras atribuições da DR eram a construção de campos de pouso no interior do país e, além disso, a operação do CAN, por meio de sua 4a Divisão, cuja sigla era DR-4. O primeiro Diretor de Rotas Aéreas, nomeado ainda em janeiro de 1942, foi o Brigadeiro Eduardo Gomes, que havia instituído o serviço do CAM dez anos antes (LAVANÈRE-WANDERLEY, 1975). Destarte, fica claro que a escolha para a DR representaria uma continuação adequada para o CAN.

Durante a Segunda Guerra Mundial, o CAN continuou prestando seus serviços. Tornava-se mais necessário do que antes, em função do racionamento de gasolina existente no país, bem como das dificuldades vividas pela navegação de cabotagem, em função da ameaça submarina do Eixo, que rondava o litoral brasileiro. (LAVANÈRE-WANDERLEY, 1975). 
Após o término da guerra, no entanto, o CAN viveu um momento de significativa expansão, em virtude do fornecimento ao Brasil de grande número de aeronaves, procedentes dos excedentes militares norte-americanos. Os principais meios aéreos de transporte, cedidos à FAB, foram o Beechcraft "Mono", o Beechcraft "Bi" e, o mais importante de todos, o Douglas C-47.

Figura 5 - aeronave Douglas C-47

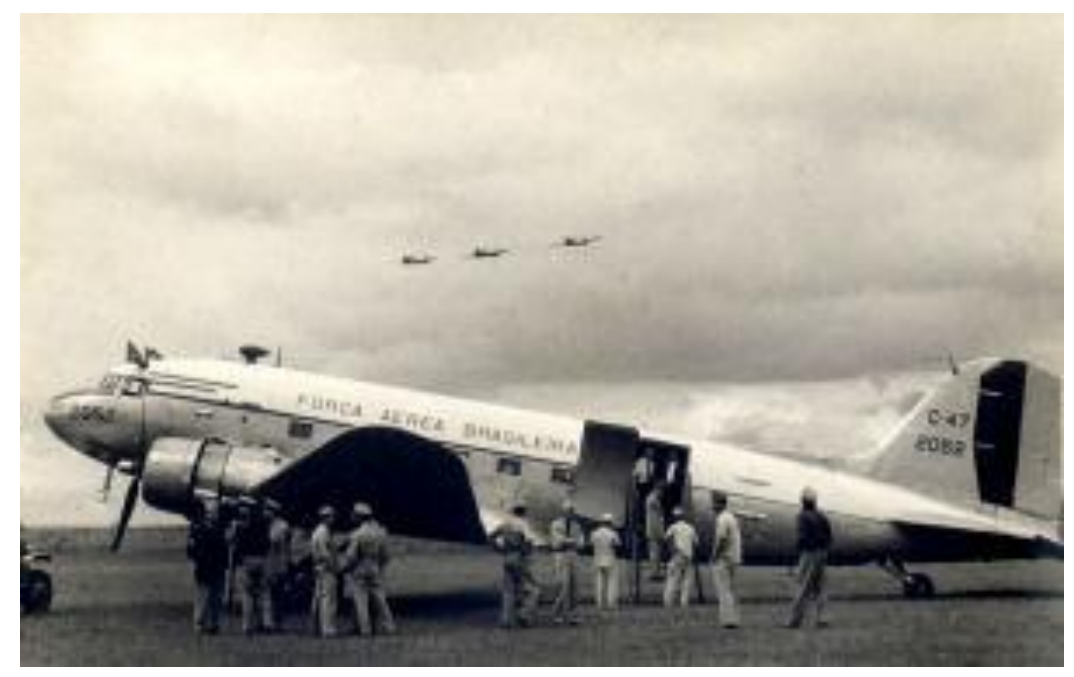

Fonte: Reservaer (2017).

O C-47, bimotor com $8 \mathrm{~h}$ de autonomia de voo, e podendo carregar 1,5 toneladas de carga ou 27 passageiros, veio a trazer significativa evolução tecnológica à Aviação de Transporte, permitindo a realização das etapas das linhas do CAN com maior segurança, pois era ainda dotado de equipamentos de rádio navegação de grande potência e confiabilidade.

A referida expansão permitiu a implantação de novas linhas para o CAN, expostas na tabela 2. 
Tabela 2 - Linhas do CAN

\begin{tabular}{|l|l|l|l|l|}
\hline \multicolumn{5}{|c|}{ LINHAS DO CAN IMPLANTADAS APÓS A SEGUNDA GUERRA MUNDIAL } \\
\hline LINHA & IMPLANTAÇÃO & \multicolumn{1}{|c|}{ INÍCIO } & FINAL & AERONAVE \\
\hline Bolívia & 19 mai 1945 & Rio de Janeiro & Santa Cruz de la Sierra & Beechcraft "Bi" \\
\hline Bolívia & 05 mar 1946 & Rio de Janeiro & La Paz & C-47 \\
\hline Acre & 1947 & Rio de Janeiro & Cruzeiro do Sul & C-47 \\
\hline Peru & 1951 & Rio de Janeiro & Lima & C-47 \\
\hline Uruguai & 1956 & Rio de Janeiro & Montevidéu & C-47 \\
\hline Equador & 1958 & Rio de Janeiro & Quito & C-47 \\
\hline EUA & 1958 & Rio de Janeiro & Washington & C-47 \\
\hline
\end{tabular}

Fonte: Lavanère-Wanderley (1975).

Em 1951, o serviço do CAN foi retirado da Diretoria de Rotas Aéreas e atribuído a uma nova organização: o Comando de Transporte Aéreo (COMTA). Esse novo comando recebeu ainda, sob sua subordinação, além do CAN, as principais Unidades Aéreas dotadas de aviões de transporte, bem como a própria Base Aérea do Galeão.

A Região Amazônica, entretanto, ainda não era integralmente servida pelo Correio Aéreo. Ainda em 1952, no mês de novembro, foi criada a Linha do Araguaia, que tinha ainda a finalidade de apoiar os postos do, na época, Serviço de Proteção ao Índio (SPI), hoje Fundação Nacional do índio (FUNAI). Essa linha, tendo como ponto de partida Belo Horizonte, passava por Uberaba, Goiânia, Aruanã, Pimentel Barbosa, Getúlio Vargas, Araguacema, Conceição do Araguaia, Las Casas e Gorotires. Com a adoção dessa rota, porção substancial da Amazônia meridional passou a ser atendida pelo Correio Aéreo, integrando-se ainda mais à nação.

A cidade de Manaus, a mais importante da Amazônia Ocidental, ainda não estava, no mesmo ano de 1952, conectada à rede do CAN. Nesse ano, foram 
levados a efeito os estudos para a implantação de duas linhas, especialmente dedicadas para essa área: a Linha Rio-Manaus e a Linha do Rio Negro; esta foi atendida pelas aeronaves anfíbias PA-10 Catalina, que haviam prestado serviços ao patrulhamento do litoral brasileiro contra a ameaça submarina, na Segunda Guerra Mundial e que, após a guerra, haviam sido concentradas na cidade de Belém, onde constituíam a unidade aérea denominada 2 o Grupo de Patrulha. (LAVANÈREWANDERLEY, 1975).

Figura 6 - Catalina CA-10

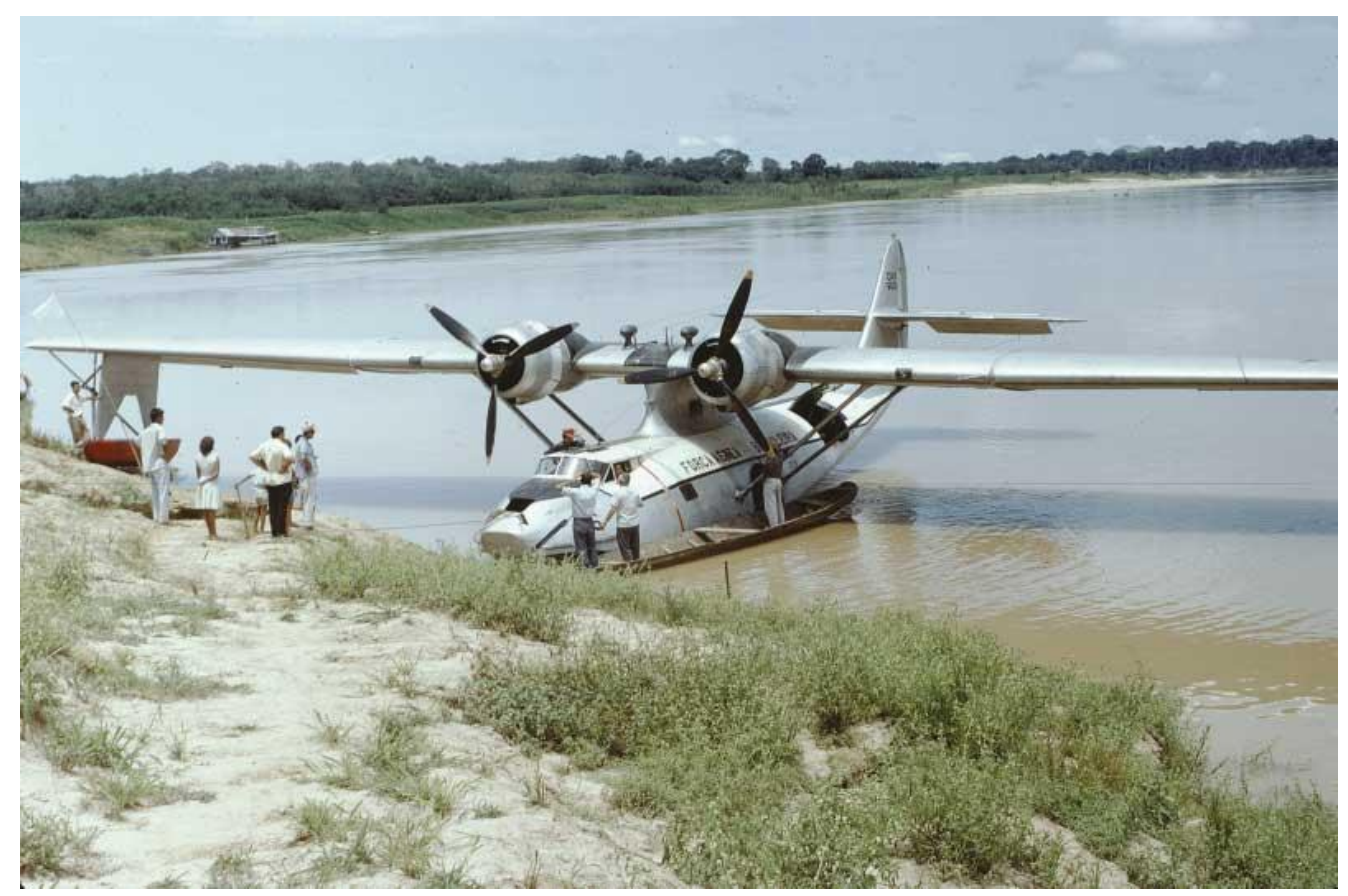

Fonte: Reservaer (2017).

Os Catalina, embora aeronaves possantes e robustas, já haviam prestado mais de doze anos de serviço à $F A B$, e estavam na configuração de Patrulha, com metralhadoras, porta-bombas e demais equipamentos bélicos. Dada a carência de aeronaves para voar na Amazônia e pousar nos seus rios, o MAer decidiu enviar os Catalina em 1958 para os Estados Unidos, a fim de serem recondicionados como aeronaves anfíbias de transporte de carga e de passageiros (LAVANÈREWANDERLEY, 1975). Surgiu assim o Catalina CA-10, versão otimizada para a atuação na Amazônia, região ainda carente de pistas, mas com abundantes vias 
navegáveis, nas quais os CA-10 poderiam pousar e decolar com facilidade. O Catalina iniciou seus serviços em 1952, e representou o maior símbolo da Integração brasileira até 1982, quando foi desativado.

A adoção do CA-10 permitiu que as linhas existentes fossem melhoradas, com maior eficácia, e que novas linhas fossem implantadas. A Linha do Solimões, por exemplo, ia de Belém até Tabatinga $(2.400 \mathrm{~km})$, servindo às localidades ribeirinhas e unidades das Forças Armadas no caminho. A Linha do Rio Negro, ligando Manaus a São Gabriel da Cachoeira $(860 \mathrm{~km})$, apoiava as missões religiosas e as populações indígenas existentes, bem como o Pelotão de Fronteira do Exército em Cucuí. Além disso, as Linhas do Rio Javari e dos rios Purus e Juruá ligavam Manaus aos Pelotões de Fronteira e às diversas localidades ao longo desses rios.

Para avaliar-se a importância do Correio Aéreo Nacional para a Integração Nacional, recorre-se, mais uma vez, a Lavanère-Wanderley,

Com o decorrer dos anos, em que foi acumulando impressionante folha de serviços, o Correio Aéreo Nacional firmou-se como um dos esteios da unidade nacional e conquistou um lugar de destaque na história do desenvolvimento social e econômico do Brasil; consagrando esse mérito, a Constituição Federal de 1946 estabeleceu, no item XI do seu Art. 5ำ, que compete à União: "manter o serviço postal e o Correio Aéreo Nacional". (LAVANÈRE-WANDERLEY, 1975, p. 161, grifos nossos).

Mas a saga do CAN não se restringiria ao continente americano. Em 1957, foi criada a Força de Emergência das Nações Unidas (United Nations Emergency Force - UNEF), na região do Sinai. O Exército Brasileiro enviou um Batalhão para a UNEF; este Batalhão precisava ser apoiado também pelo CAN. Assim, foi criada a Linha de Suez, pelo Aviso Ministerial nำ 21, de 11 de fevereiro de 1957. Essa linha foi mantida pelos únicos aviões quadrimotores de que a FAB então dispunha, os B17 Fortalezas Voadoras. Até o ano de 1960, ocasião em que entraram em serviço as aeronaves C-54, a linha foi mantida pelos B-17, com uma viagem mensal. Em 1967, em função da retirada da UNEF, a Linha de Suez foi desativada.

Assim se refere Lavanère-Wanderley em respeito à obra do CAN,

No trabalho do Correio Aéreo Nacional, além do dever do cumprimento das missões dentro do quadro de uma organização militar, existe um senso de apostolado, existe uma grande disposição para prestar socorro aos entes humanos enfermos ou necessitados e para prestar ajuda aos brasileiros 
que, lutando em regiões desprovidas de recursos, procuram atingir um estágio mais avançado de civilização e desenvolvimento. (LAVANÈREWANDERLEY, 1975, p. 162).

Muito embora seu alcance nacional e internacional, na Amazônia o CAN foi utilizado em sua plenitude, mercê das distâncias e das carências da região.

Figura 7 - aeronave Catalina na Amazônia - apoio aos religiosos e aos indígenas

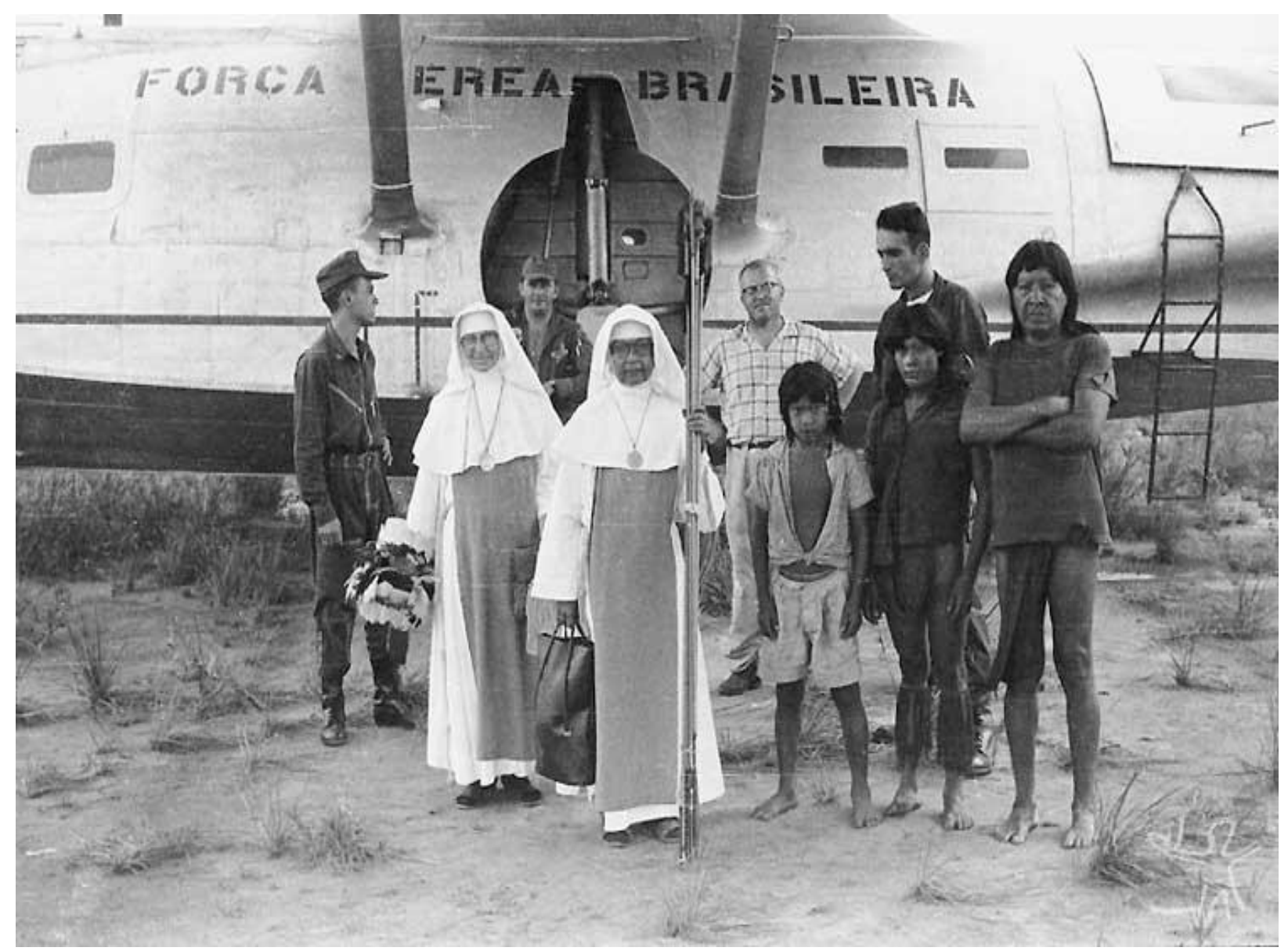

Fonte: Reservaer (2017).

A imagem anterior (Figura 7) como que sintetiza o Correio Aéreo e parte dos que por ele eram apoiados: as populações indígenas e as missões religiosas. 


\section{CONCLUSÃO}

Verificou-se como, ao longo do tempo, o Correio Aéreo Nacional (CAN) veio a agregar atividades de caráter humanitário e assistencial às suas atribuições originais de integração nacional e de adestramento de pilotos.

Procedeu-se à descrição dos fatos e das circunstâncias históricos que levaram à criação da Aviação do Exército e da Marinha; seguidos do panorama da criação do Correio Aéreo, como fator de adestramento militar e de integração nacional. O crescimento e desenvolvimento do CAN foram analisados em seguida, e contemplou a passagem pela Segunda Guerra Mundial, e pela introdução das linhas do CAN na Amazônia. A partir desse enfoque, pôde-se perceber como, sobretudo na região citada, o CAN passou a ter um forte viés de assistência social, demonstrando como o Correio Aéreo prestava apoio inclusive às populações indígenas e às missões religiosas. Reforçando as palavras de Lavenère em 1918, "o Correio Aéreo Nacional firmou-se como um dos esteios da unidade nacional e conquistou um lugar de destaque na história do desenvolvimento social e econômico do Brasil".

\section{REFERÊNCIAS}

BRASIL. Aviso no 1.463, 21 de novembro 1918. Aprova a Escola de Aviação Militar, 1918.

FUNDAÇÃO GETÚLIO VARGAS. Centro de Pesquisa e Documentação de História Contemporânea do Brasil. Café. Rio de Janeiro, [2010]. Disponível em: http://cpdoc.fgv.br/sites/default/files/verbetes/primeira-republica/CAF\%C3\%89.pdf. Acesso em: 20 nov. 2017.

LAVANÈRE-WANDERLEY, Nélson Freire. História da Força Aérea Brasileira. Rio de Janeiro: Gráfica Brasileira, 1975.

LORCH, Carlos. Do CAN ao SIVAM: a FAB na Amazônia. Rio de Janeiro: Aerospace, 2000.

PERISSINOTTO, Renato Monseff. A República e a modernização do Estado de São Paulo. Cadernos da Faculdade de Filosofia e Ciências - UNESP, Marília, v. 9, n. 2, 2000. 
RESERVAER. Clube Virtual dos Militares da Reserva e Reformados da Aeronáutica. Brasília, 2017. Disponível em: http://www.reservaer.com.br/. Acesso em: 20 nov. 2017.

Recebido em 02/10/2019.

Aceito em 04/12/2019. 